\title{
Study for The Impact of Some Problems Facing Female Owners of Small Household Projects in All Fields, and its Relationship to Improve the Standard of Family Living Sahloul,T. M.M. ${ }^{1}$; Yousria A. A. Moneim ${ }^{2}$; Dina H. Alepeshoty ${ }^{1}$ and Samar M. El Sharkawy ${ }^{1}$ ${ }^{1}$ Department of Home Economics - Faculty of Specific Education - Damietta University \\ ${ }^{2}$ Department of Home Economics - Faculty of Agriculture - Alexandria University
}

\section{دراسة أثر بعض المشكلات التى تواجه صاحبات المشروعات المنزلية الصغيرة فى مختلف المجالات وعلاقتها بتحسين مستوى معيشة الأسرة

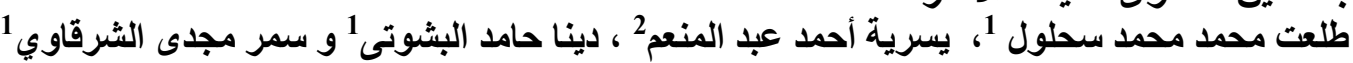

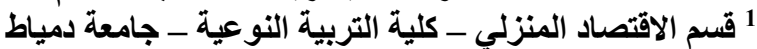

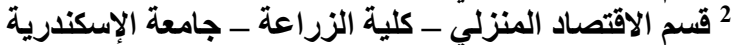

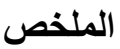

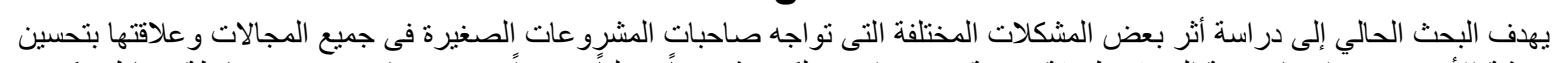

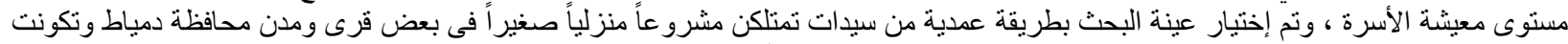

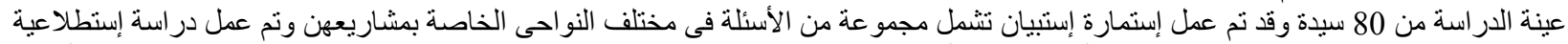

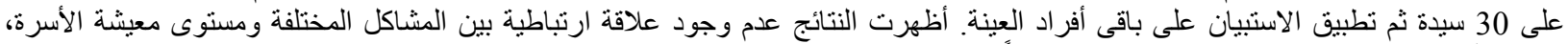

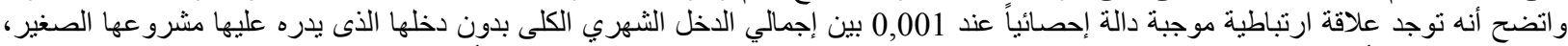

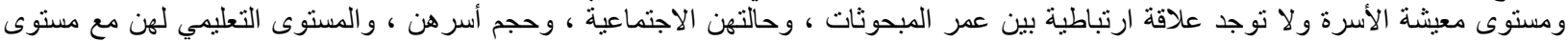

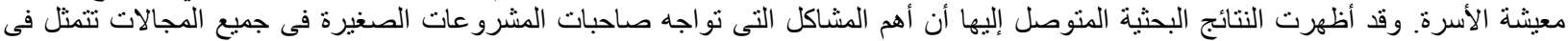

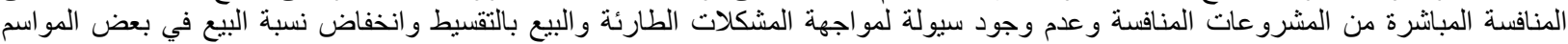

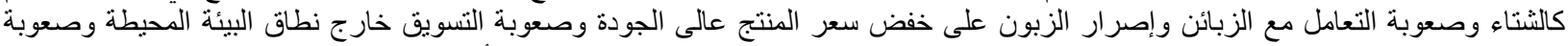

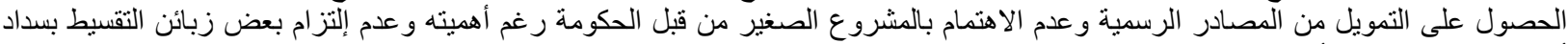

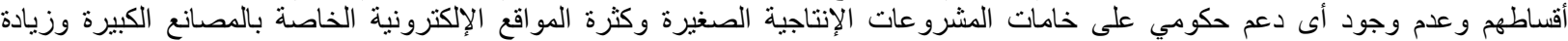

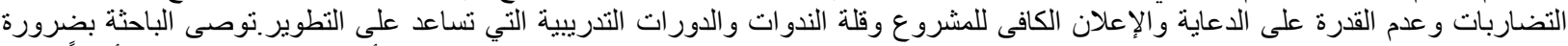

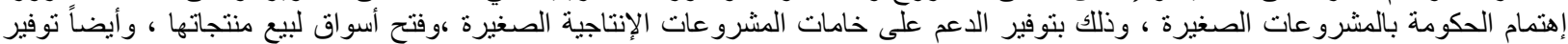
الندوات و الدور ات التى تساعد على التُوعات التطوير.

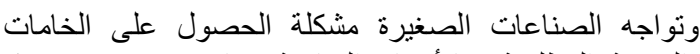

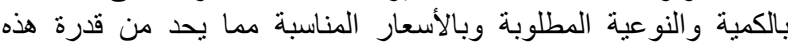

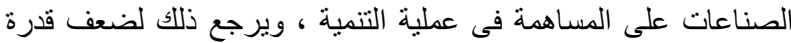

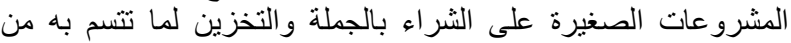

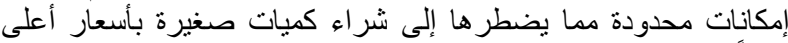

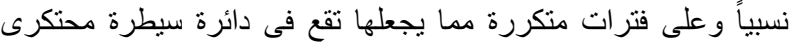

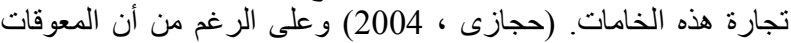

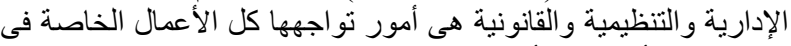

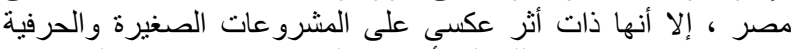

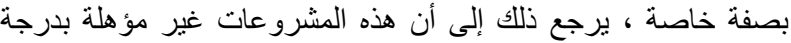

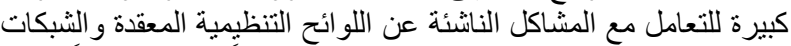

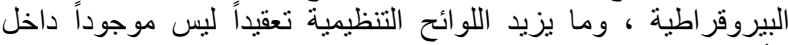

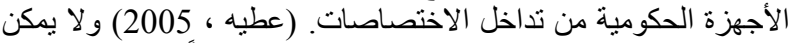

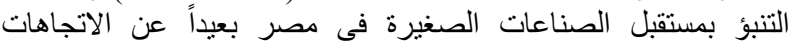

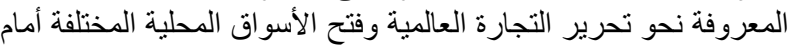

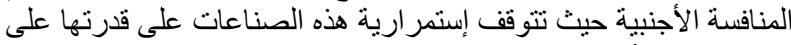

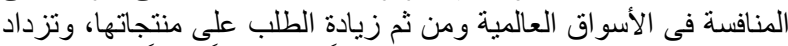

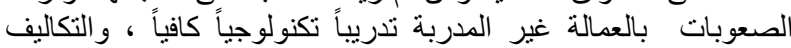

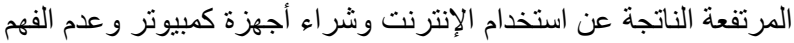

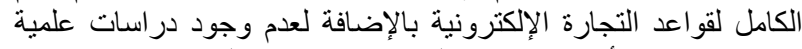

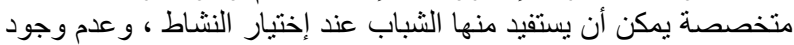

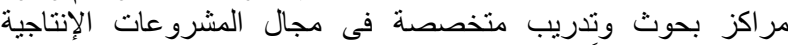

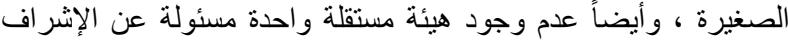

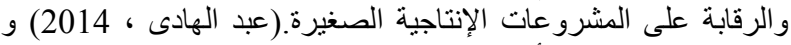

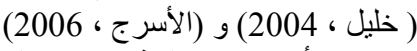
و أوضحت دراسة (هبه نصار ، 2004) 2004) أن المشكلات التمويلية

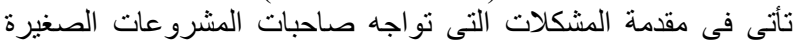

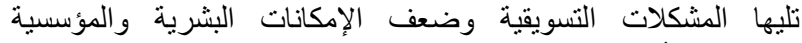

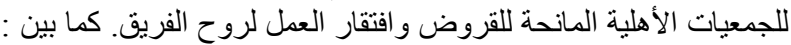

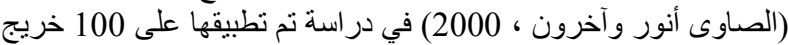

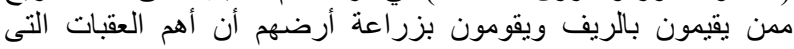

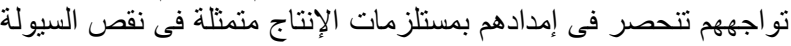

\section{المقدمة و المشكلة البحثيه}

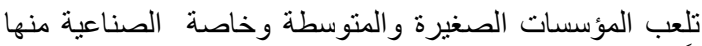

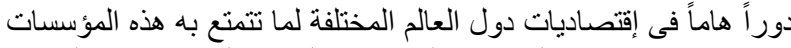

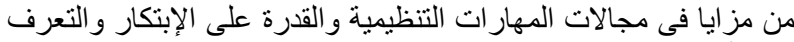

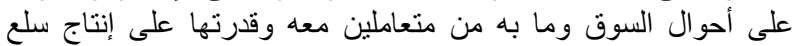

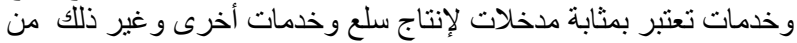

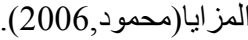

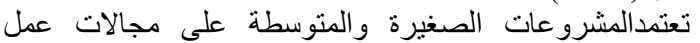

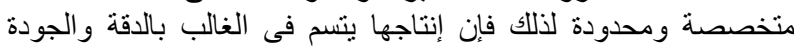

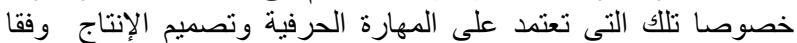

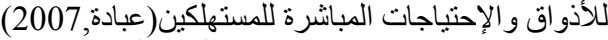

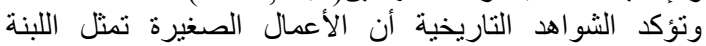

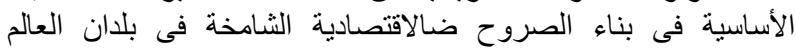

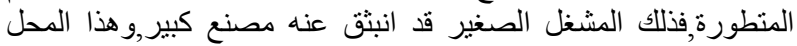

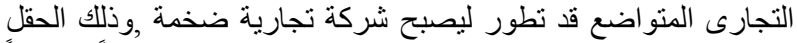

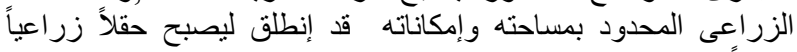
واسعاً (حرب 2006) (200).

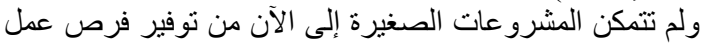

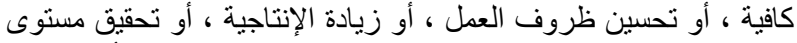

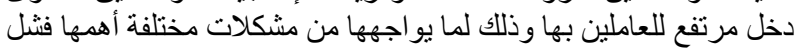

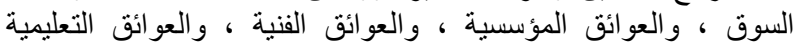

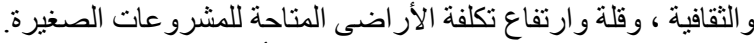

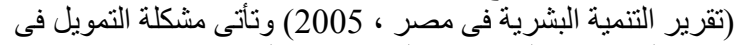

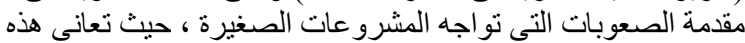

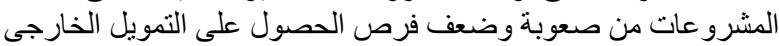

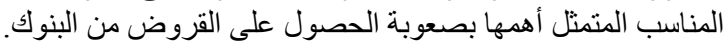
(محمد ، 2015)

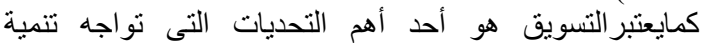

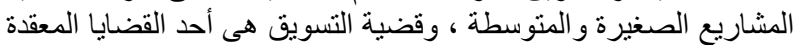

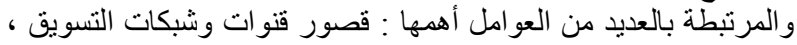

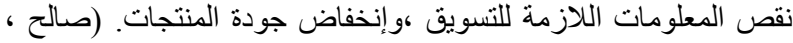




\section{Sahloul,T. M.M. et al.}

الصغير بالطابع اليدوى ، واحتياجاته من خامات البيئة تكون متعددة ،

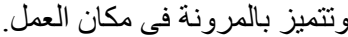
يقصد بالمبحوثات إجرائياً:

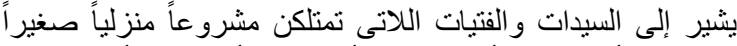

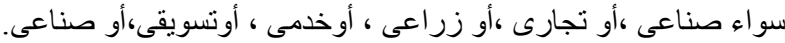

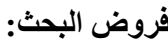

1- توجد علاقة إرتباطية بين مستوى معيثة الأسرة كمتغير تابع وبين

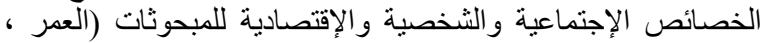

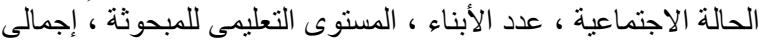

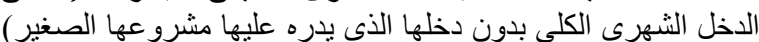

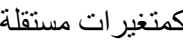

2-نوجد علاقة إرتباطية بين مستوى معيشة الأسرة كمتغير تابع وبين

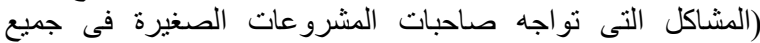

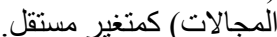

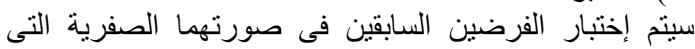
تنص بأنه لاتوجد علاقة.

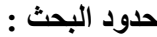

تقتصر حدود البحث على ماند ما يلى:

أولاً: الحد البشرى:عينة تلكون من من (80) سيدة من سيدات محافظة دمياط

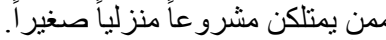

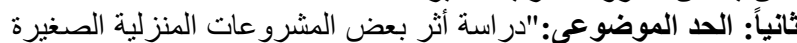

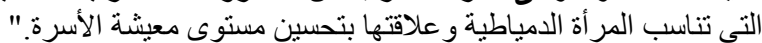

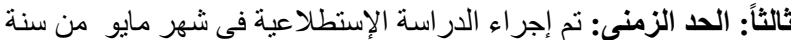

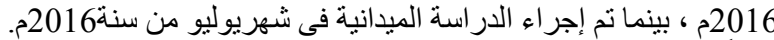
رابعاً: الحد المكانى: بعض إند قرى حضر محافظة دمياطفبالنسبة للقرى نم

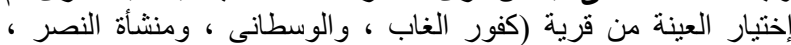

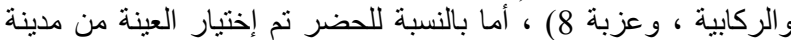
(دمياط الجديدة ، ودمياط ، و الزرقا وفارسكور ، وميت أبو غالبة لإن).

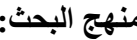

يعتمد البحث الحالى على المنهج الوصفى التحليلى الذى يهن مئم

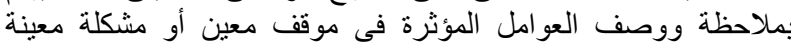
بالإضافة إلى إهتمامه بتحليل الظروف الكون فيائنة و الممارسات السائدة.

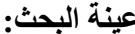

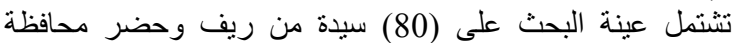

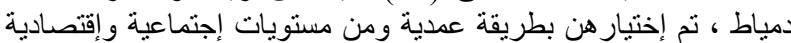

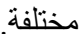

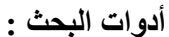
اشتملت أدوات البحث : البحث على:

1- إستمارة إستبيان الخصات الخصائص الثخصية والاجتماعية والاقتصادية

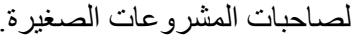

2-إستمارة المشاكل المختلفة التى تو اجه صاحبات المشرو عات الصغيرة

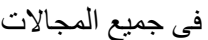

وتشتمل الاستمارة الأولى على 5 أسئلة توجه لسيدات العينة بهدف

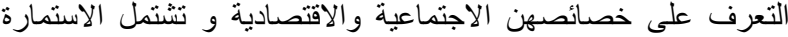

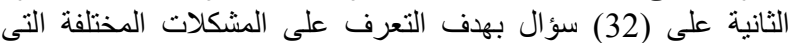

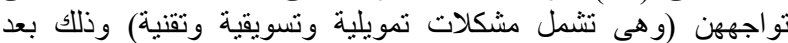

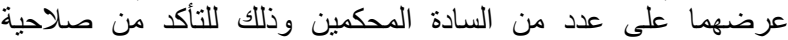

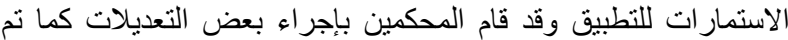

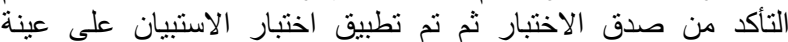
إستطلاعية قوامها 30 سيدة لحساب معامل الثبار نبات وكان وكانت النتيجة 0.98 وتعتبر هذه القيمة من معاملات الثبات المبات المرتفعة.

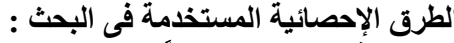

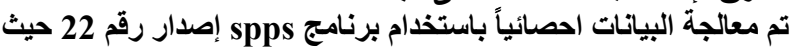

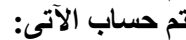

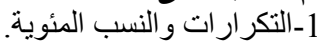
2- 2-المتوسط و الانحر اف المعيارى. 3-اختبار "تحليل التباين الأحادى".

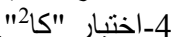

\section{النتائَج والمناقشات}

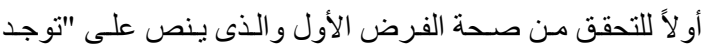

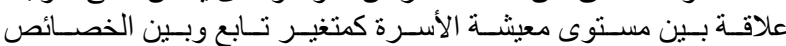

المادية ، وارتفاع أسعار العلف ونقص فى الأدوية البيطرية ويعتبر

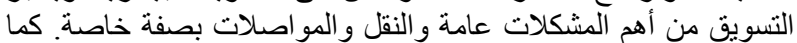
أوضحت در اسة (إبر اهيم ، 2000) أن الصناعات عات الصنات الصغيرة فى محافظة

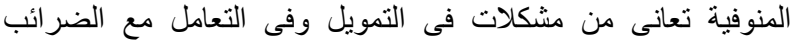

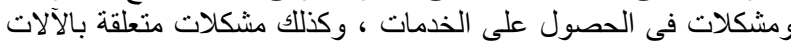

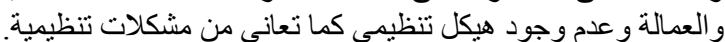

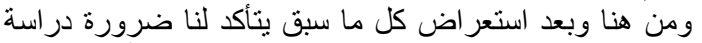

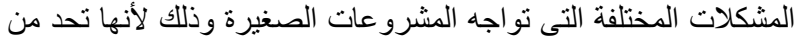

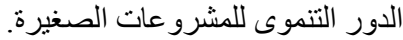

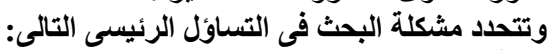

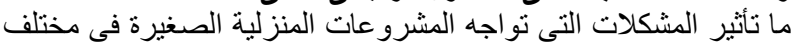

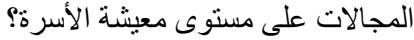
ويتفرع من هذا التساؤل التساؤ لات التالية الألية:

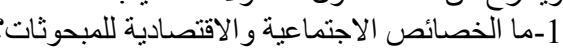

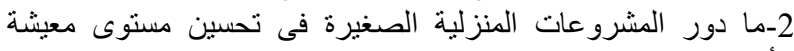

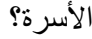

3-ما المشكلات التى تعترض تقدم المشرو عات المنزلية الصغيرة؟

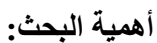

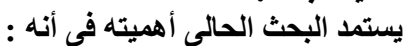

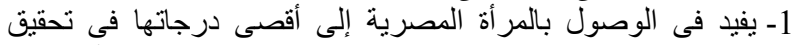

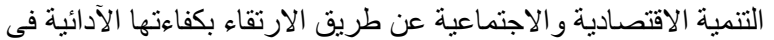

مجال عملها بالمشرو عات الصغية الصغيرة.

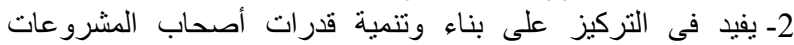

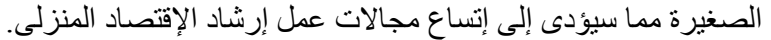

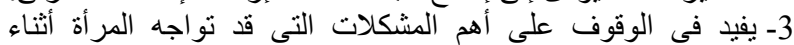

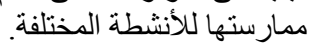

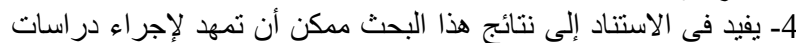

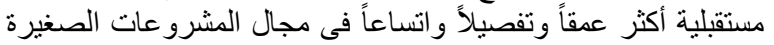

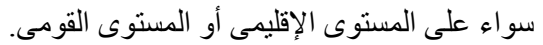

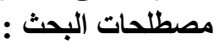

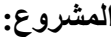

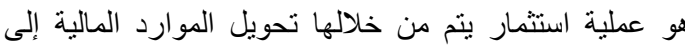

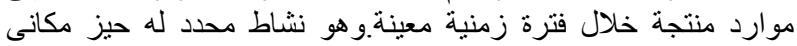

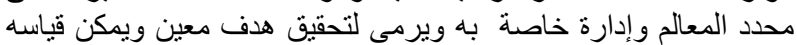

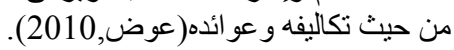

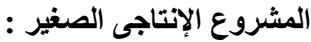

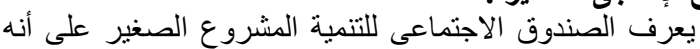

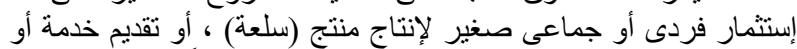

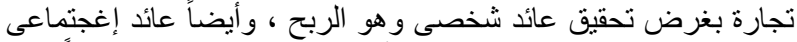

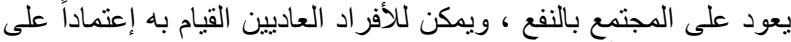

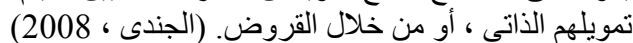

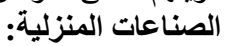

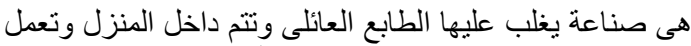

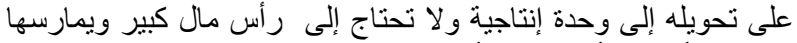

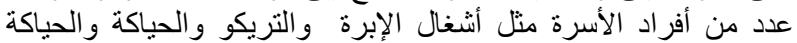

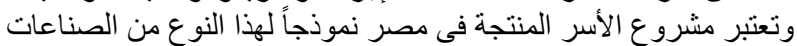

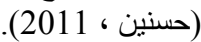

التنمية الاقتصادية للأسرة:

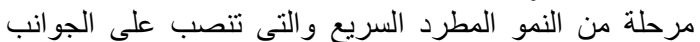

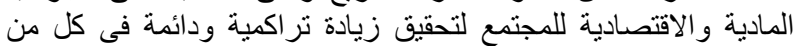

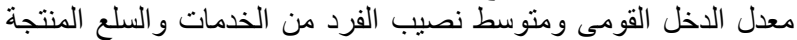

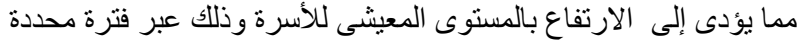

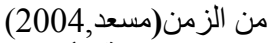
مستوى معيشة الأسرة:

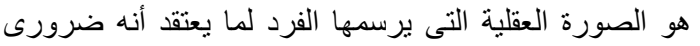

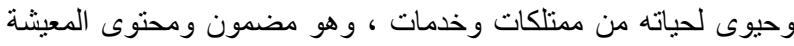

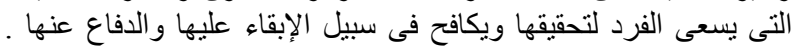
(الطوبشى ، 2011) المشروع الصغير إجرائياً:

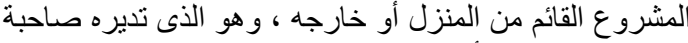
المشروع ، ويعتمد على رأس مال صنير المنز ، ويتميز إنتاج المشروع لثيره 


\section{J. Agric. Econom. and Social Sci., Mansoura Univ., Vol.7 (11), November,2016}

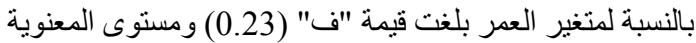

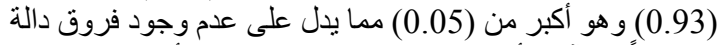

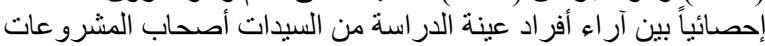

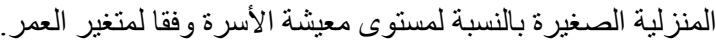

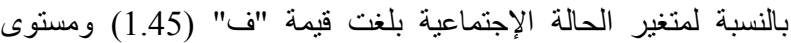

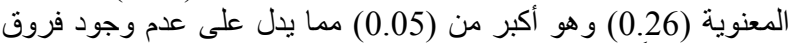

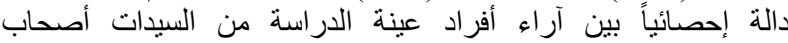

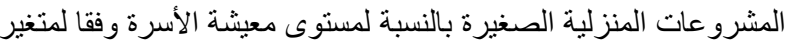
الحالة الإجتماعية.

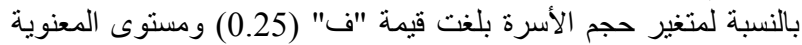

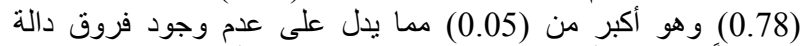

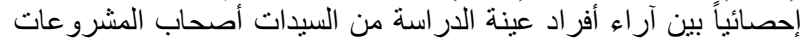

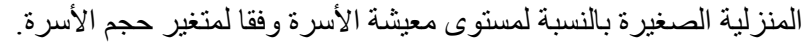

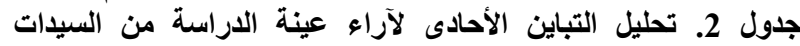

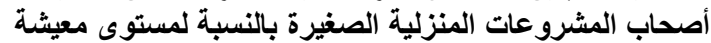

\begin{tabular}{|c|c|c|c|c|c|c|c|}
\hline & & بحوتًات. & عليمى للا & وى الذ & ها للمع & مرن وف & \\
\hline الإحصائية & المعنوية & "ف"التحسوبة & المعيارى الاف & المتوسط & $\%$ & ن & التعليمي \\
\hline \multirow{8}{*}{ غيردال } & \multirow{8}{*}{0.39} & \multirow[b]{7}{*}{1.07} & 10.82 & 56.00 & 6.25 & 5 & أمية \\
\hline & & & 8.78 & 59.50 & 7.50 & 6 & تقر أوتكتب \\
\hline & & & 10.11 & 61.50 & 10.00 & 8 & \\
\hline & & & 11.26 & 66.25 & 10.00 & & ثانوية عامة \\
\hline & & & 10.29 & 61.43 & 28.75 & 23 & مؤهل متوس \\
\hline & & & - & 62.00 & 1.25 & فوق 1 & متو سو \\
\hline & & & 11.72 & 67.25 & 30.00 & 24 & مؤهل جامع \\
\hline & & & 13.86 & 62.20 & 6.25 & فوق 5 & مؤهل \\
\hline
\end{tabular}

بالنسبة لمتغير المستوى التعليمى بلغت قيمة "فئ (1.07) (1.05)

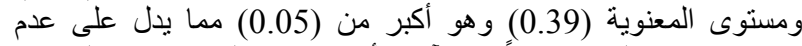

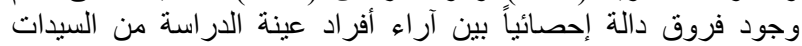

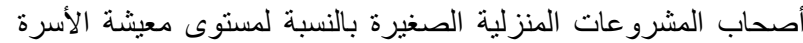
وفقا لمتغير المستوى التعليمى.

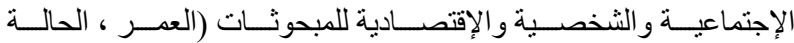

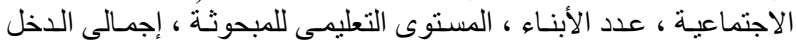

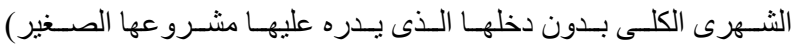
كمتغير ات مستقلة".

وفيما يلى عرض ات لما تم التوصل إليه من نتائج:

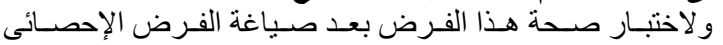

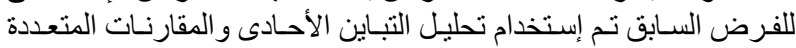

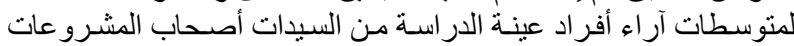

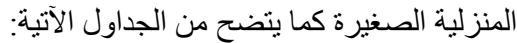

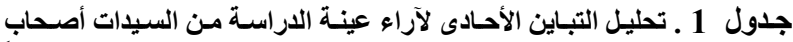

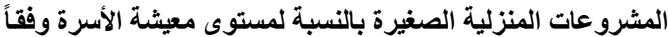
للخصائص الشخصية والاجتماعية للمبحوثات.

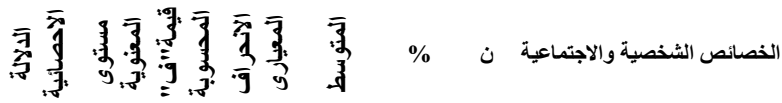

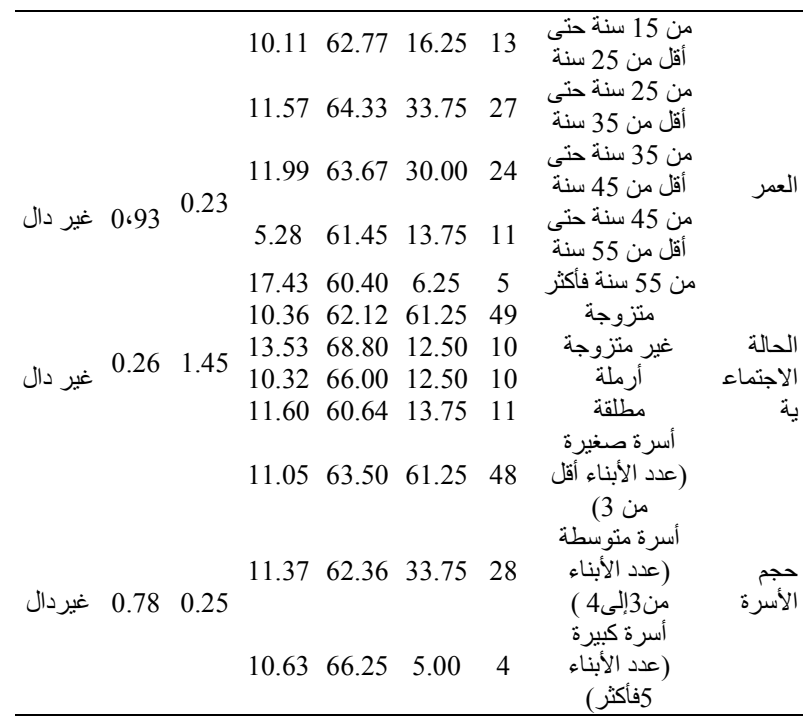

جدول 3. تحليل التباين الأحادى لآراء عينة الدراسة من السيدات أصحاب المشروعات المنزلية الصغيرة بالنسبة لمستوى معيثة الأسرة وفقاً

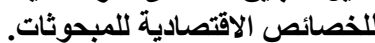

\begin{tabular}{|c|c|c|c|c|c|c|c|c|}
\hline الإحصائية & المعنوية & قالمحسوبة "ف" & 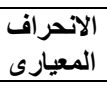 & المتوسط & $\%$ & ن ن & & الخصائص الاقتصادية \\
\hline & & & 12.11 & 60.46 & 16.25 & 13 & أقلّل من 500جنيه شهرياً & \\
\hline & & & 7.90 & 61.46 & 46.25 & 37 & (دون دخل من 500 جنيه شهرياً 1200 جنى أقل من & إلجمالى الدخل الثهرى الثش \\
\hline & & & 11.68 & 64.12 & 32.50 & 26 & أقل من 1200 5000جنيه شهرياً حتى شياً & \\
\hline دال & 0.001 & 5.83 & 11.63 & 83.00 & 5.00 & 4 & من 5000 جنيه فأكثر شهرياً & \\
\hline
\end{tabular}

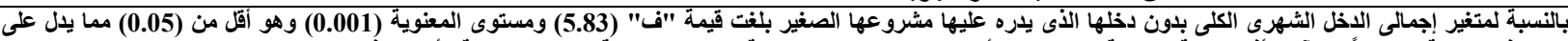

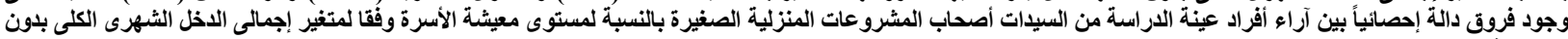
لخلها الذى يدره عليها مشروعها الصغير.

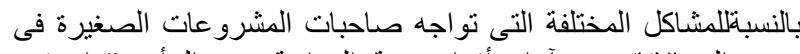

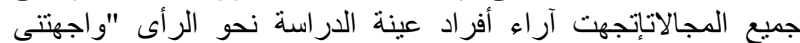

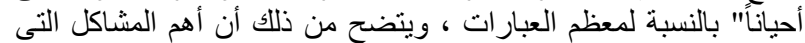

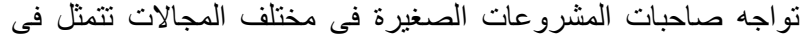

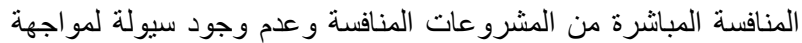

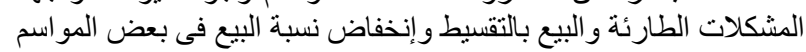

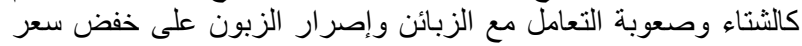

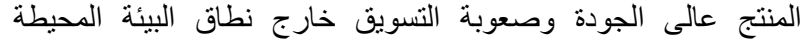

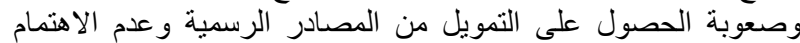

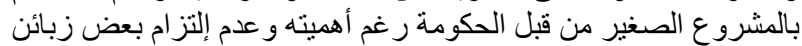

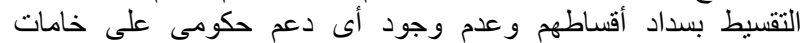

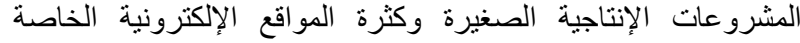

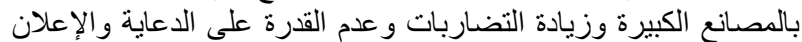

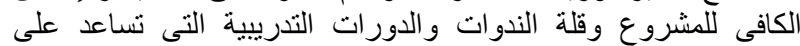

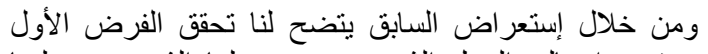

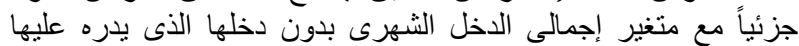

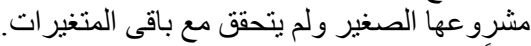

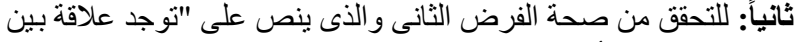

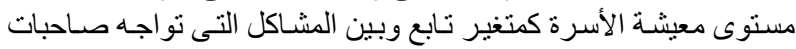

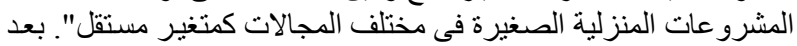

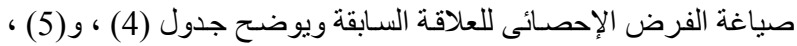
و(6) النتائج التى تم التوصل الإنى إليها.

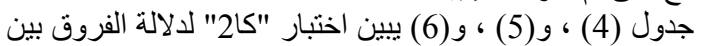

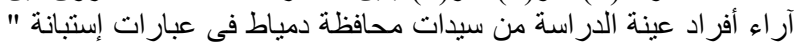

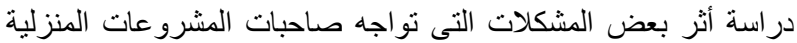

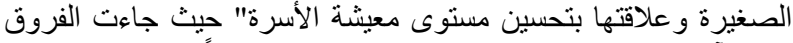

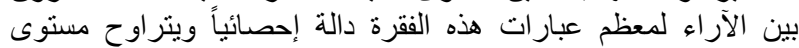
المعنوية بين (0.046 - 0.001) وجاءت الناء النتائج على النحو النالى : 
Sahloul,T. M.M. et al.

جدول 4. يوضحالفروق بين آراء أفراد عينة الدراسة من سيدات محافظة دمياط بالنسبة للمشكلات المالية

\begin{tabular}{|c|c|c|c|c|c|c|c|c|c|}
\hline \multirow{2}{*}{ الحسابى الوسط } & \multirow{2}{*}{ المعنوية } & \multirow[t]{2}{*}{ كا } & \multicolumn{2}{|c|}{ 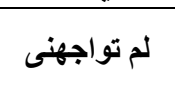 } & \multicolumn{2}{|c|}{ واجهتنى أحياناً } & \multicolumn{2}{|c|}{ واجهتى كثيراً } & \multirow[t]{2}{*}{ 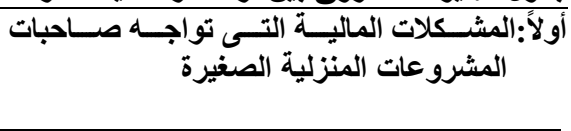 } \\
\hline & & & $\%$ & $ت$ & $\%$ & $ت$ & $\%$ & $ت$ & \\
\hline 1.93 & 0.001 & 16.30 & 47.50 & 38 & 12.50 & 10 & 40.00 & 32 & صعوبة الحصول على التمويل من المصنادر \\
\hline 1.75 & 0.001 & 19.60 & 55.00 & 44 & 15.00 & 12 & 30.00 & 24 & إرتفاع أسعار الآلات والمعدات والمواد الخام \\
\hline 1.45 & 0.001 & 51.93 & 71.25 & 57 & 12.50 & 10 & 16.25 & 13 & إرتفاع أجور العمالة \\
\hline 1.51 & 0.001 & 50.28 & 70.00 & 56 & 8.75 & 7 & 21.25 & 17 & فو ائد القروض للمقترضين \\
\hline 1.90 & 0.522 & 1.30 & 37.50 & 30 & 35.00 & 28 & 27.50 & 22 & بعض زبائن التقسيط لا يلتزموا بسداد أقساطهم \\
\hline 1.49 & 0.001 & 57.93 & 72.50 & 58 & 6.25 & 5 & 21.25 & 17 & تهرب البنوك من تقديم المساعدات المالية اللازمة \\
\hline 1.43 & 0.001 & 59.28 & 73.75 & 59 & 10.00 & 8 & 16.25 & 13 & تعقيد الإجر اءات اللازمة للإقتر اض \\
\hline 2.14 & 0.046 & 6.18 & 21.25 & 17 & 43.75 & 35 & 35.00 & 28 & عدم وجود سيولة لمو اجهة المشكلات الطارئة \\
\hline 1.59 & 0.001 & 30.93 & 62.50 & 50 & 16.25 & 13 & 21.25 & 17 & الاحتفاظ بالفو اتير وسجلات العمل \\
\hline 1.85 & 0.001 & 26.73 & 53.75 & 43 & 7.50 & 6 & 38.75 & 31 & المشرو وجود أى دعم حكومى على الإنتاجية الصغيرة خامات \\
\hline
\end{tabular}

جدول 5. يوضح الفروق بين آراء أفراد عينة الدراسة من سيدات محافظة دمياط بالنسبة للمشكلات التسويقية

\begin{tabular}{|c|c|c|c|c|c|c|c|c|c|}
\hline الوسط & مستوى & $2 ! 5$ & \multicolumn{2}{|c|}{ لم تواجهنى } & \multicolumn{2}{|c|}{ واجهتى أحيانًاً } & \multicolumn{2}{|c|}{ واجهتى كثيراً } & \multirow[b]{2}{*}{ ثُانياً:المشكلات التسويقية } \\
\hline 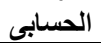 & المعنوية & كا & $\%$ & $ت$ & $\%$ & $ت$ & $\%$ & $ت$ & \\
\hline 2.13 & 0.321 & 2.28 & 28.75 & 23 & 30.00 & 24 & 41.25 & 33 & البيع بالتقسبط \\
\hline 1.96 & 0.373 & 1.98 & 38.75 & 31 & 26.25 & 21 & 35.00 & 28 & صعوبة التسويق خارج نطاق البيئة المحيطة \\
\hline 1.83 & 0.086 & 4.90 & 45.00 & 36 & 27.50 & 22 & 27.50 & 22 & عدم القدرة على الدعاية و الإعلان الكافى للمشروع \\
\hline 2.16 & 0.015 & 8.43 & 31.25 & 25 & 21.25 & 17 & 47.50 & 38 & المنافسة المباشرة من المشروعات الأخرى \\
\hline 1.60 & 0.001 & 43.23 & 66.25 & 53 & 7.50 & 6 & 26.25 & 21 & عدم فتح قنوات تصدير منتجات المشرو عات الصغيرة \\
\hline 1.90 & 0.001 & 20.80 & 50.00 & 40 & 10.00 & 8 & 40.00 & 32 & والصينية منافسة من منتجات أجنيية أخرى كالمنتجات \\
\hline 1.75 & 0.003 & 11.73 & 51.25 & 41 & 22.50 & 18 & 26.25 & 21 & المسته خروج الدعاية عن منتج المشروع بشكل يجذب \\
\hline 1.75 & 0.019 & 7.90 & 47.50 & 38 & 30.00 & 24 & 22.50 & 18 & عدم وجود أفكار جديدة أو مبتكرة لجذب الزبائن \\
\hline 2.13 & 0.212 & 3.10 & 30.00 & 24 & 27.50 & 22 & 42.50 & 34 & إنخفاض نسبة البيع فى بعض المو اسم كالثتاء \\
\hline 2.06 & 0.039 & 6.48 & 23.75 & 19 & 46.25 & 37 & 30.00 & 24 & صعر المنتج عالى الجع الزبائن و إصر ار الزبون على خفض \\
\hline 1.68 & 0.001 & 24.78 & 58.75 & 47 & 15.00 & 12 & 26.25 & 21 & و التر اثية لارتفاع عكلى بعض المنتجات اليدوية ذات القيمة العالية \\
\hline 1.73 & 0.001 & 24.70 & 57.50 & 46 & 12.50 & 10 & 30.00 & 24 & 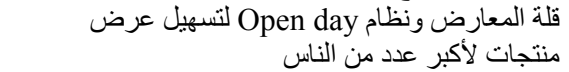 \\
\hline
\end{tabular}

جدول 6. يوضح الفروق بين آراء أفراد عينة الدراسة من سيدات محافظة دمياط بالنسبة للمشكلات التقنية

\begin{tabular}{|c|c|c|c|c|c|c|c|c|c|}
\hline الوسط الوسطى & المعنوية & كا2 & اجن اجنى & 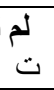 & ـ أحيانًاً & 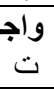 & كثيرً & تو & ثالثاً:المشكلات التقنية \\
\hline 1.21 & 0.001 & 96.18 & 85.00 & 68 & 8.75 & 7 & 6.25 & 5 & 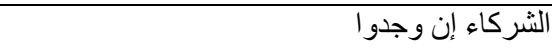 \\
\hline 1.74 & 0.001 & 13.53 & 52.50 & 42 & 21.25 & 17 & 26.25 & 21 & على التعامل مع تكنولوجيا المعلومات \\
\hline 1.59 & 0.001 & 23.73 & 58.75 & 47 & 23.75 & 19 & 17.50 & 14 & نقص الخبرة الفنية اللازمة للمشروع \\
\hline 1.44 & 0.001 & 55.53 & 72.50 & 58 & 11.25 & 9 & 16.25 & 13 & قلة العمالة الفنية المدربة \\
\hline 1.74 & 0.003 & 11.58 & 51.25 & 41 & 23.75 & 19 & 25.00 & 20 & إقتناع المستهلكين بقلة جودة المنتج المحلى \\
\hline 1.73 & 0.001 & 13.98 & 41.25 & 33 & 45.00 & 36 & 13.75 & 11 & إهمال النواحى الأسرية ور عاية الأبناء \\
\hline 1.78 & 0.006 & 10.30 & 50.00 & 40 & 22.50 & 18 & 27.50 & 22 & قالتطوير الندو ات \\
\hline 1.91 & 0.001 & 18.48 & 48.75 & 39 & 11.25 & 9 & 40.00 & 32 & رغم أهميته الاتمام بالمشروع الصغير من قبل الحكومة \\
\hline 1.41 & 0.001 & 55.23 & 72.50 & 58 & 13.75 & 11 & 13.75 & 11 & الصغيرة و البحث عن العمال المهرة العمل بالمشرو الكبيرة عات \\
\hline 1.84 & 0.001 & 20.73 & 52.50 & 42 & 11.25 & 9 & 36.25 & 29 & وزيادة التضواقع الإلكترونية الخاصة بالمصانع الكبيرة \\
\hline
\end{tabular}

-وجود علاقة بين مستوى معيشة الأسرة ، و إجمالى الدخل الثهرى (دون

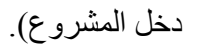

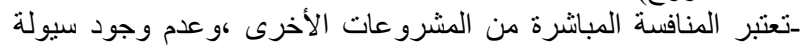

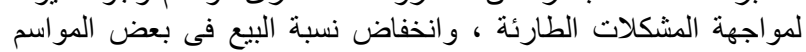

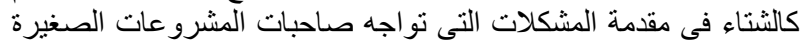

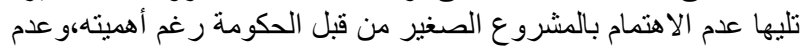
ومن خلال استعر اض السابق يتضح لنا عدم تحقق الفرض الثانى مع متغير مستوى معيشة الأسرة. النتائج الأنزة

ـعدم وجود علاقة بين مستوى معيشة الأسرة ،و (العمر ، الحالة الإجتماعية ،حجم الأسرة ،و المستوى التعليمى) للمبحوثات. 


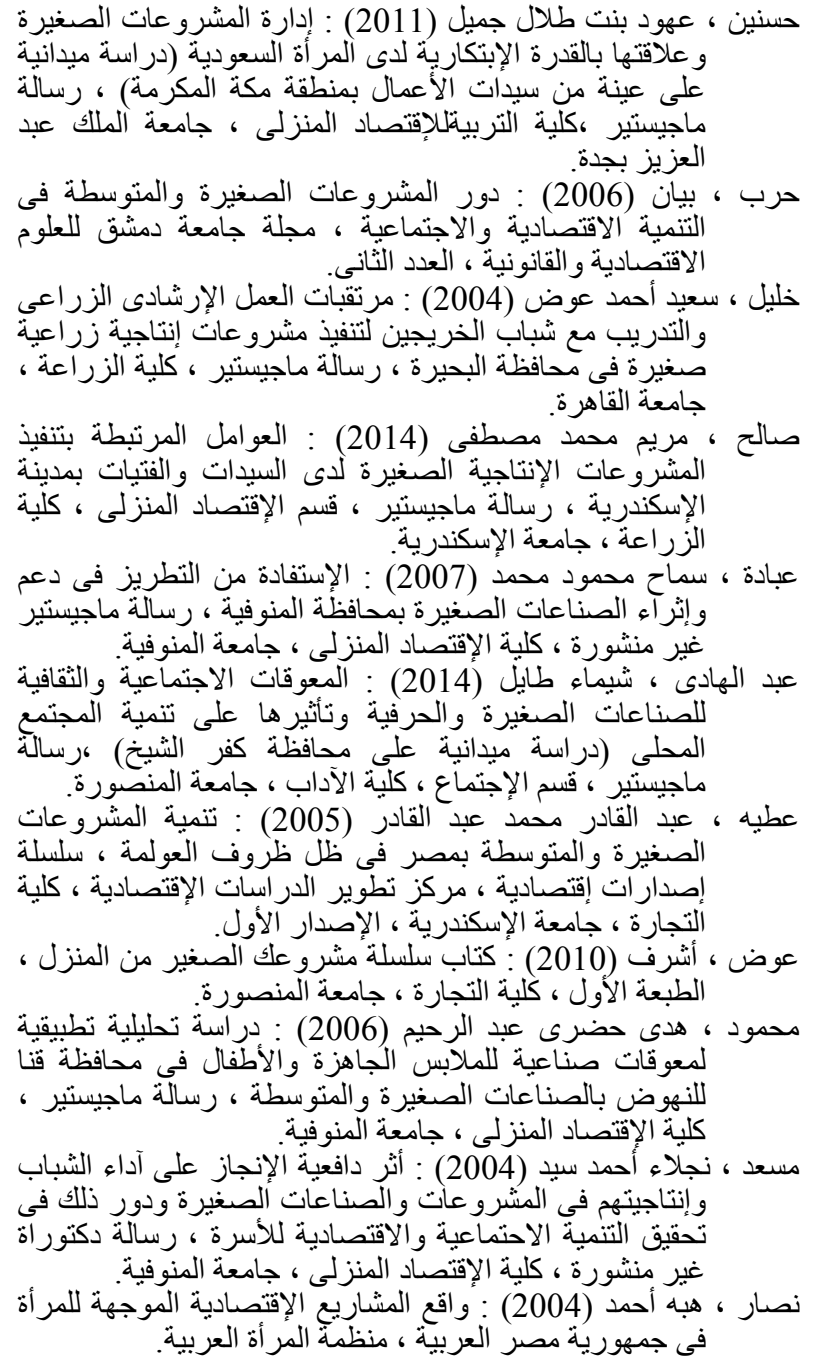

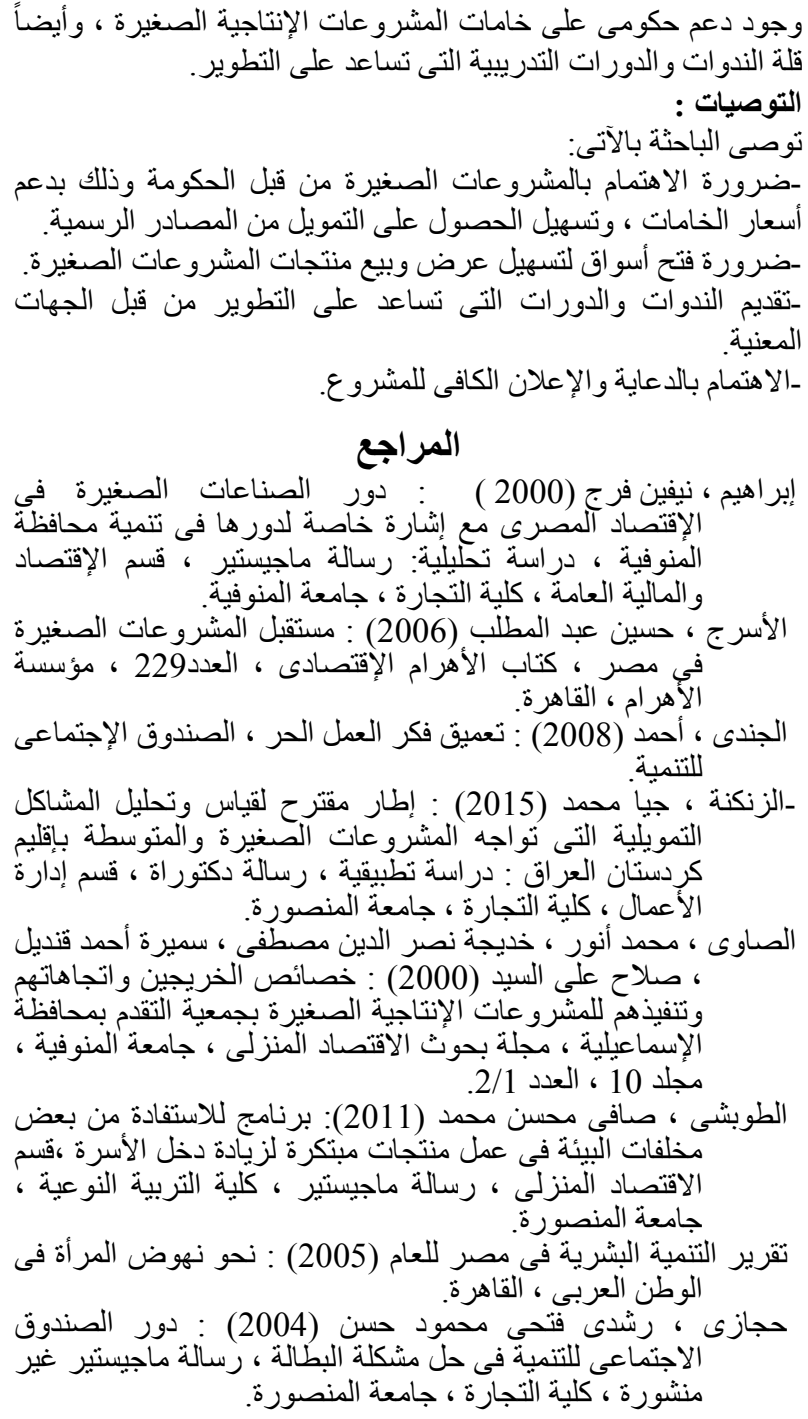

\section{Study for The Impact of Some Problems Facing Female Owners of Small Household Projects in All Fields, and its Relationship to Improve the Standard of Family Living Sahloul,T. M.M. ${ }^{1}$;ousria A. A. Moneim ${ }^{2}$; Dina H. Alepeshoty ${ }^{1}$ and Samar M. El Sharkawy ${ }^{1}$ ${ }^{1}$ Department of Home Economics - Faculty of Specific Education - Damietta University \\ ${ }^{2}$ Department of Home Economics - Faculty of Agriculture - Alexandria University}

\section{ABSTRACT}

The present research aimed to study the impact of some of the various problems facing female owners of small household projects in all fields, and its relationship to improving the standard of family living. the research sample selection was by intentional way of ladies owns of small household project some rural and urban Damietta Governorate and the study sample consisted of 80 woman. and prepared questionnaire includes a set of questions in various aspects of own projects and exploratory study was conducted on 30 women and then apply the questionnaire to the rest of sample. The results showed no correlation between various problems and the standard of family living, It turned out that there was a positive correlation statistically significant at .001 between total monthly income without the income from her small project and the standard of family living, and there is no correlation between the age of the sample members and marital status of them, family members, the educational level of them with the standard of family living. The research results obtained showed that the most important problems facing female owners of small household projects in all fields was direct competition from similar projects, lack of liquidity to face the emergent problems, installment sales, low rate of sales in some seasons like winter, the difficulty of dealing with customers and the insistence of the customer on reduce the price of the high quality product, difficulty of marketing outside range of the surrounding environment, the difficulty in obtaining funding from official sources, lack of government's attention to the small project despite its importance, some Installment customers' lack of commitment to pay installments, And the absence of any government support on raw materials of small productive projects, the large number of big factories own websites, the speculation rising, lack of sufficient advertising for the project and Lack of seminars and training courses that help development.Researcher recommends the need for the government's attention to small projects by providing support ores for small productive projects and openning markets for buying its products also providing seminars and courses which help to development. 